\title{
A Comparative Study of Swim-up and Upstream Methods for Isolating Sperm Cell for Intra Uterine Insemination
}

\author{
Farhang Abed ${ }^{1,2^{*}}$, Shahrzad Zadehmodarres ${ }^{1,2}$
}

\begin{abstract}
Objectives: Sperm cell preparation is an important step in the advanced treatment of infertility. Among the different methods introduced, none are considered to be ideal. The common methods are based on utilizing centrifugal separation which has been proven to be harmful to the sperm cell. We developed a method, based on the motion against the flow of sperm cell, which can successfully separate active sperm cells.

Materials and Methods: In this study, we investigated the efficacy of this approach with a randomized clinical trial. Fifty-one candidates for the intra uterine insemination (IUI) treatment participated in our study. Twenty-five cases were assigned to our test group, separating the sperm cells using the proposed method (upstream method), and the conventional swim-up method was applied to 26 cases in our control group. The entire process of IUI treatment in both groups was exactly the same except for the methods of separating sperm cells.

Results: Results showed that the pregnancy rate using the new method was $20 \%$, while the common method of sperm cell preparation resulted in $15.3 \%$ pregnancy rate.

Conclusion: The new sperm preparation method (Upstream method) can be used as a simple, quick and effective method of sperm cell separation in fertility treatment especially in IUI procedure.

Keywords: Intra Uterine Insemination, Sperm, Sperm preparation, Swim-up, Upstream
\end{abstract}

\section{Introduction}

There are more than 80 million infertile couples around the world (1). It is estimated that about 40 million of infertile couples are currently seeking infertility treatments (2). Treatment of infertility ranges from simple advice on natural conception to complex and expensive interventions including Assisted Reproductive Technologies (ART) (3). Advanced infertility treatment methods are costly and most people especially in developing countries are deprived of such treatments $(4,5)$. Even in a developed country like Canada, this costly treatment seems to suit only those who could afford it (6).

Along with ART the most common form of medical intervention to treat infertility is Intra Uterine Insemination (IUI), whereby prepared sperm cells are deposited directly into a woman's uterus to aid conception (3). Approximately $30 \%$ of the infertility cases are unexplained (7). Most experts consider IUI as the primary treatment for unexplained infertility (8). Several studies attest to the effectiveness of IUI and it is considered a simple and inexpensive fertility treatment (9). It is also reported that these same characteristics had allowed IUI procedure to be performed by nurses with comparable results to those performed by physicians (10).

We think that augmented use of IUI procedure, in general, and easier application of the procedure in medical offices, in particular, demands for simpler and inexpensive processes that would not require specialist and sophisticated equipment for preparing sperm cells.

Currently, swim-up and density gradient are the standard methods of sperm cell separation and in some cases glass wool filtration method is also used. In these techniques, considerable amount of active sperm cell with normal morphology and high fertility potential can be separated (11). All of these methods require the use of centrifugal separation. Aitken and Clarkson discovered that centrifugal separation could result in producing free radicals which subsequently could damage the sperm cell. Following a thorough review of the results of researches in this area, Mortimer also concluded that the preparation methods which used centrifugal separation could damage the sperm cell, decrease its fertility potential, and reduce the rate of pregnancy (12).

Previously we observed that when sperm cells were exposed to the flow of fluid, their randomized movement changed to organized and synchronized swim against the

Received 4 November 2014, Accepted 3 January 2015, Available online 13 February 2015

${ }^{1}$ Infertility and Reproduction Health Research Center, Shahid Beheshti University of Medical Sciences, Tehran, Iran. ${ }^{2}$ Sabohi Infertility Center, Mahdieh Hospital, Tehran, Iran.

*Corresponding author: Farhang Abed, Sabohi Infertility Center, Mahdieh Hospital, Tehran, Iran. Tel:+982155301452, Email: abedfar@yahoo.com 
stream $(13,14)$. Cilia have been shown to be present in the endometrial cells of mammals. Cilia are the important components of reproductive system which exist in the endometrial cells of mammals. Ciliary stream in the fallopian tubes and uterus is in the same direction and flows all the way towards the external os. We hypothesized that this streaming current leads the sperm cells towards the fertilization site at the ampoule of the fallopian tubes. Moreover, this streaming current acts as a natural selective mechanism in which allows only those sperms that are healthy and motile to reach the fertilization site (13). Recently, Miki and Clapham (15) and Kantsler et al. (16) confirmed our earlier suggestion.

Based on our theory and findings we created a sperm cell separating device for the upstream method. Our previous study had shown its efficacy in separating normal motile sperm cell (17). In this study we examined the success rate of IUI procedure using the two methods of sperm cell separation, i.e. swim-up and upstream.

\section{Materials and Methods}

Among all the infertile patients who attended Sabohi Infertility Center of Mahdieh Hospital, 51 candidates for IUI treatment were selected. Based on their initial clinical evaluation IUI candidates were selected if they were $<30$ years old and causes of infertility were cervical factor, mild to moderate male factor, ovulation factor or unexplained infertility. In addition, patients were excluded if they had recurrent abortion, history of genetic disease, endometriosis, uterine myoma and history of more than 3 previous unsuccessful IUI cycles.

The conventional sperm preparation, swim-up method, was used for 26 individuals. The sperm preparation method used for the remaining 25 candidates was upstream method. From the 3 rd to the 5 th day of their cycle patients took $100 \mathrm{mg}$ Clomiphene tablets daily. From day 6 they received 75-150 IU HMG/day. Vaginal ultrasound procedure was performed between days 8-12 of their cycle. If the size of the dominant follicles were between 16-18 $\mathrm{mm}$, they would be injected with additional 10,000 units of HCG. Patients returned to the hospital after 36 hours and were prepared for IUI procedure.

Patients were randomly and anonymously placed in the two trial groups, i.e. swim-up and upstream groups. The only difference between the two groups was the pattern of sperm preparation performed for each group. Otherwise the rest of the process was exactly the same, e.g. the same type of catheter and the same method of injection were used.

Ahead of the preparation process, semen samples underwent evaluation process according to the WHO recommendation described in detail in the joint European Society of Human Reproduction and Embryology-Nordic Association for Andrology (ESHRE-NAFA) manual (18). Initial sperm concentration and motility were marked under a $400 \times$ magnifier. Mobility assessment was done according to four classification groups which are rapid progressive, slow progressive, non-progressive and immo- tile sperm count. At the end, the percentages reached from two categories (rapid progressive + slow progressive) were printed on the sample report. The morphology of spermatozoa was subsequently determined. Each spermatozoon without morphological "defects" was defined as ideal. Any deficits in comparison to the ideal spermatozoon were classified as defects. Head, neck/mid-piece and tail deficits are the registered defects on the structure of a sperm (i.e. three defects). A spermatozoon can be affected by one or all of these defects, but it is still counted as one defected cell. Only complete healthy spermatozoa, i.e. those with both head and tail, were counted. All imperfect cases were categorized as defective.

\section{Upstream method}

The device (Figure 1) used for the upstream method is a plastic tube which is divided to two compartments by a nylon mesh (TechWin Ltd, Iran).

Using a Pasteur pipette $2 \mathrm{ml}$ of semen was deposited on the nylon mesh. Using a pipette, $1 \mathrm{ml}$ of "Ham's F-10" media was gently added to it. The device was then transferred to an incubator and remained there for 30 minutes. While in the incubator, under its own weight, the semen migrated through the nylon mesh to the bottom chamber. The active sperm cells swam against the semen's flow and entered into the cultivation environment. In the end, only the cultivation environment which contained the active sperm cells remained in the upper chamber. Through tilting the device the sperm cells were then transferred to a $6 \mathrm{ml}$ falcon tube for analysis and inseminated into patient's uterus.

\section{Swim-up method}

In this method $2 \mathrm{ml}$ of sperm cell and $2 \mathrm{ml}$ of "Ham's F-10" media were mixed in a falcon tube and centrifuged for 10 minutes. The supernatant was then removed and again $2 \mathrm{ml}$ of "Ham's F-10" media was added to the pellet and centrifuged for 10 minutes. Later the supernatant was removed and then slowly $1 \mathrm{ml}$ of media was added to the pellet. The tube was subsequently transferred to a $\mathrm{CO}_{2}$ incubator. The tube remained there for 45 minutes, later removed from the incubator and $0.5 \mathrm{ml}$ of the media from the top of the tube was removed and used for the

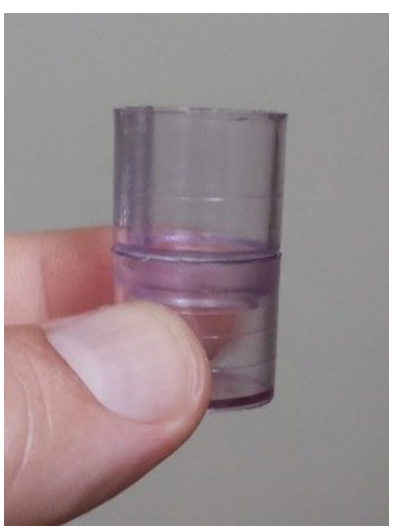

Figure 1. Upstream device. 


\section{IUI procedure.}

\section{Results}

The collected data was analyzed by pair T-Test analysis and Chi-squared analysis; values of $\mathrm{P}$ greater than 0.05 were considered significant.

Table 1 compares the result of sperm parameters using swim-up method with those of upstream method. The difference in the number of sperm cells per unit of measure, the percentage of sperm cells with normal morphology, and their motility rate are statistically significant.

Table 2 illustrates the differences between patient's characteristic of the two applied methods. It particularly shows that the pregnancy rate among those in the swim-up group was 15\%, 4 of 26 cases; whereas, the rate of pregnancy among those in the upstream group was 20\%, 5 of 25 cases. However, statistically, the variation between the two groups was not significant.

\section{Discussion}

Today, there is a need for simple and low-cost methods of treating infertility that is affordable for couples with low income around the world. The use of inexpensive and simple treatment methods will encourage politicians and insurance organizations to step-up their efforts in developing strategies that facilitate the implementation of such methods (8). If used appropriately, IUI is a simple method with acceptable success rate to combat infertility (9).

Normally, inside the female reproductive system the fertile sperm cells actively deviate from other sperm cells and enter into the cervical mucus (19). In this process active and motile sperm cells are separated and undergo certain physiological changes called "competency ability", which is a vital and fundamental step for fertility $(20,21)$.

Probably Australia's Alexander Lopata was the first pioneer of sperm cell separation. He noticed that placing the

Table 1. Result of sperm parameters Swim-Up versus Upstream methods

\begin{tabular}{lcccccc}
\hline & \multicolumn{3}{c}{ Before processing } & \multicolumn{3}{c}{ After processing } \\
\cline { 2 - 7 } & Motility & Counts & NM & Motility & Counts & NM \\
\hline Upstream & $56.2 \%$ & 67.4 & $51 \%$ & 90 & 47.9 & $75 \%$ \\
Swim-up & $51.2 \%$ & 53 & $49 \%$ & 95 & 34.4 & $86 \%$ \\
\hline
\end{tabular}

$\mathrm{NM}=$ Normal morphology

Table 2. Patient's characteristic of the two applied methods

\begin{tabular}{lcc}
\hline & Swim-up & Upstream \\
\hline Average patients age & 27.8 & 28 \\
Average duration of infertility & 4.3 & 4.47 \\
Average No. of folicules $>16 \mathrm{~mm}$ & 3 & 2 \\
Average of previous IUI cycles & 1 & 1.6 \\
No. of chemical pregnancies & $5(19.2)$ & $6(24 \%)$ \\
No. of clinical pregnancies & $4(15.3 \%)$ & $5(20 \%)$ \\
No. of IUI Cycles & 26 & 25 \\
\hline
\end{tabular}

tip of a Pasteur pipette containing culture media in a semen container for one hour results in active sperm cells entering the pipette. This method allowed him to separate and collect a considerable volume of normal and active sperm cells (22).

The launch of IVF procedure in the 80 s resulted in the emergence of various sperm cell separation methods. Since the introduction of swim-up method by Mahadevan and Baker (23), more sophisticated separation methods were developed in order to increase the number of captured active sperm cells. These methods could be categorized as migration method, density gradient method, and filtration method $(24,25)$.

The results of our study showed that swim-up method and upstream method were both capable of separating sufficient number of active and normal sperm cells for IUI procedure. However, there was considerable difference in the motility rate and normal morphology of sperm cells between the two methods. Obviously, in both methods, the number of separated sperm cells would ultimately be less than the total initial number of sperm count due to the elimination of abnormal and immotile sperm cells.

Although, from the stand point of the sperm cell parameters before and after preparation process, the two separation methods did not differ significantly in pregnancy rate, nevertheless, the rate among patients in the upstream group was higher compared to those in the swim-up group, i.e. $16 \%$ in the swim-up group and $20 \%$ in the upstream group. However, due to the relatively small number of participants in our trial, i.e. 51 candidates for IUI procedure, this result cannot be considered significantly meaningful.

Whether or not the upstream method could lead to higher success rate of pregnancy, at the very least, its advantage is with the simplicity of the equipment, and simpler training requirements and operating process. Additionally, limiting the use of aggressive physical intervention in the process to a minimum reduces the risk of damage to healthy sperm cells.

\section{Conclusion}

The new office based sperm preparation method (upstream method) can be used as a simple, quick and effective method of sperm cell separation in fertility treatment especially in IUI procedure. The authors believe that the promising results of this preliminary study should inspire further investigation and comparison of the results in a larger scale and through the collaboration of multiple fertility centers.

\section{Ethical issues}

This study was approved by the Medical Ethical Committee of Shahid Beheshti University of Medical Sciences and written consents were obtained from all the participants.

\section{Financial support}

This study was supported by Iran National Science Foundation (ISFN) and Fertility \& Infertility Health Research 
Center of Shahid Beheshti University of Medical Sciences.

\section{Conflict of interests}

The authors declare that only Farhang Abed has a financial interest in this study and Shahrzad Zadehmodarres does not have any financial or proprietary interest in any material or method mentioned.

\section{Acknowledgments}

The authors express their sincere appreciation for the support received from the staff at Sabohi Infertility Center of Mahdieh Hospital. Our special thanks to Mrs. Mahmudi and Miss. Esmaeilian for their tireless efforts in support of this project. Also we would like to thank Mrs. Mitra Nikfarjam for grammatical editing of this manuscript.

\section{References}

1. Fatallah MF. Reproductive health: a global overview. Early Hum Dev 1992;29:35-42.

2. Boivin J, Bunting L, Collins JA, Nygren KG. International estimates of infertility prevalence and treatment-seeking: potential need and demand for infertility medical care. Hum Reprod 2007;22(6): 1506-12. doi: 10.1093/humrep/dem046.

3. Chambers GM, Hoang VP, Zhu R, Illingworth PJ. A reduction in public funding for fertility treatmentan econometric analysis of access to treatment and savings to government. BMC Health Serv Res 2012;12:142. doi: 10.1186/1472-6963-12-142.

4. van Balen F, Gerrits T. Quality of infertility care in poor-resource areas and the introduction of new reproductive technologies. Human Reprod 2001;16(2):215-9.

5. Nachtigall RD. International disparities in access to infertility services. Fertil Steril 2006; 85(4):871-5.

6. Nisker J. Distributive justice and infertility treatment in Canada. J Obstet Gynaecol Can 2008 30(5):425-31.

7. Templeton AA, Penney GC. The incidence, characteristics, and prognosis of patients whose infertility is unexplained. Fertil Steril 1982;37(2):17582.

8. Ombelet W, Campo R. Affordable IVF for developing countries. Reprod Biomed Online 2007;15(3):257-65.

9. Zadehmodarres S, Oladi B, Saeedi S, Jahed F, Ashraf H. Intrauterine insemination with husband semen: an evaluation of pregnancy rate and factors affecting outcome Intrauterine insemination with husband semen: an evaluation of pregnancy rate and factors affecting outcome. J Assist Reprod Genet 2009;26(1):7-11. doi: 10.1007/s10815-008-9273-7.

10. Klein JU, Kuleta D, Petrozza JC. Intrauterine insemination (IUI) outcomes in cases performed by nurses as compared with cases performed by physicians. Fert Steril 2007;88:S9-S10.

11. Paasch U, Grunewald S, Glander HJ. Sperm selection in assisted reproductive techniques. Soc Reprod Fertil Suppl 2007;65:515-25.

12. Mortimer D. Sperm preparation techniques and iatrogenic failures of in-vitro fertilization. Hum Reprod 1991;6(2):173-6.

13. Abed F. The new finding of a phenomenon in sperm motility; the spermatozoa swims against flow, Proceeding of the 10th World Congress of In Vitro Fertilization and Assisted Reproduction editors: Victor Gomel and Peter CK leung Monduzzi Editors, 1997.

14. Abed F. Developing a rapid and simple method of sperm preparation for intracytoplasmic sperm injection (ICSI). MEFS J 2001;6:212-5.

15. Miki K, Clapham DE. Rheotaxis guides mammalian sperm cell. Curr Biol 2013;23(6):443-52. doi: 10.1016/j.cub.2013.02.007.

16. Kantsler V, Dunkel J, Blayney M, Goldstein RE. Rheotaxis facilitates upstream navigation of mammalian sperm cells. Elife 2014;3:e02403. doi: 10.7554/eLife.02403.

17. Abed F. Upstream; a novel method for separating human motile sperms. Iranian J Reprod Med 2009;7(3):141-4.

18. Kvist U, Bjo"rndahl L. Manual on Basic Semen Analysis. ESHRE Monographs. Oxford: Oxford University Press; 2002.

19. Mortimer D. Mortimer D. Sperm Transport in the Human Female Reproductive Tract. In: Finn CA, editor. Oxford Reviews of Reproductive Biology. Vol. 5. Oxford: Oxford University Press; 1989. p. 30.

20. Bedford JM. Significance of the need for sperm capacitation before fertilization in eutherian mammals. Biol Reprod 1983;28(1):108-20.

21. Yanagimachi R. Mammalian Fertilization. New York: Raven Press; 1988.

22. Lopata A, Patullo MJ, Chang A, James B. A method for collecting motile spermatozoa from human semen. Fertil Steril 1976;27(6):677-84.

23. Mahadevan M, Baker G. Assessment and preparation of semen for in vitro fertilization. In: Wood C, Trounson A, editors. Clinical In Vitro Fertilization. Berlin: Springer Verlag;1984. p. 83-97.

24. Henkel RR, Schill WB Sperm preparation for ART. Reprod Biol Endocrinol 2003;1:108.

25. Mortimer D. Sperm preparation methods. J Androl 2000;21(3):357-66.

Copyright $@ 2015$ The Author(s); This is an open-access article distributed under the terms of the Creative Commons Attribution License (http://creativecommons.org/licenses/by/4.0), which permits unrestricted use, distribution, and reproduction in any medium, provided the original work is properly cited. 